\title{
Entre o desenvolvimento e a decolonialidade: Santarém, os portos e os conflitos
}

\author{
Between development and decoloniality: Santarém, ports and conflicts
}

\section{Entre el desarrollo y la decolonialidad: Santarém, los puertos y los conflictos}

\section{Entre developpement et decolonialite: Santarém, portos et conflits}

\author{
Thiago Henrique Costa Silva ${ }^{1}$ \\ Renata Priscila Benevides de Sousa ${ }^{1}$ \\ Fabiana Ferreira Novaes ${ }^{2}$ \\ João da Cruz Gonçalves Neto
}

Recebido em 02/01/2018; revisado e aprovado em 25/03/2018; aceito em 13/04/2018

DOI: http://dx.doi.org/ 10.20435/inter.v0i0.1799

\begin{abstract}
Resumo: Este artigo apresenta um debate sobre o desenvolvimento e reconhecimento através do método materialista histórico dialético, em uma perspectiva decolonial, adotando como metodologia a pesquisa bibliográfica, documental e jurisprudencial, que subsidia uma análise crítica do projeto portuário da EMBRAPS em Santarém, PA. Evidencia-se a existência de um pensamento ocidental hegemônico de desenvolvimento, que privilegia a busca do crescimento econômico a qualquer custo, inclusive social e ambiental. Por fim, concluise que a forte herança eurocêntrica implica desequilíbrio entre os ideais daqueles que se beneficiam desse modelo economicista, as empresas portuárias, e daqueles que permanecem marginalizados no processo, as comunidades quilombolas de Santarém.
\end{abstract}

Palavras-chave: desenvolvimento real; desenvolvimento econômico; decolonialidade; reconhecimento; projetos portuários.

Abstract: This article presents a debate on the development and recognition through the dialectical historical materialist method, in a decolonial perspective, adopting as methodology the bibliographical, documentary and jurisprudential research, with the purpose of do a critical analysis of the port project of EMBRAPS in Santarém, PA. It was evidenced the existence of a Western hegemonic thinking of development, which favors the pursuit of economic growth at any cost, including social and environmental. Finally, it was concluded that the strong Eurocentric heritage implies an imbalance between the ideals of those who benefit from this economistic model, the port companies, and those who remain marginalized in the process, the quilombola communities of Santarém.

Keywords: real development; economic development; decoloniality; recognition; port projects.

Résumé: Cet article présente un débat sur le développement et la reconnaissance à travers la méthode matérialiste historique dialectique, dans une perspective décoloniale, en adoptant comme méthodologie la recherche bibliographique, documentaire et jurisprudentielle qui subventionne une analyse critique du projet portuaire de EMBRAPS à Santarém, PA. II est démontré l'existence d'une pensée hégémonique occidentale du développement, qui favorise la poursuite de la croissance économique à tout prix, y compris sociale et environnementale. Enfin, il est conclu que le fort héritage eurocentrique implique un déséquilibre entre les idéaux de ceux qui bénéficient de ce modèle économique, les entreprises portuaires, et ceux qui restent marginalisés dans le processus, les communautés quilombolas de Santarém.

Mots clés: développement réel; développement économique; la décolonialité; reconnaissance projets portuaires.

Resumen: Este artículo presenta un debate sobre el desarrollo y el reconocimiento a través del método materialista histórico dialéctico, en una perspectiva decolonial, adoptando como metodología la investigación bibliográfica, documental y jurisprudencial, que subsidia un análisis crítico del proyecto portuario de EMBRAPS en Santarém, PA. Se evidencia la existencia de un pensamiento occidental hegemónico de desarrollo, que privilegia la búsqueda del crecimiento económico a cualquier costo, incluso social y ambiental. Por último, se concluye que la fuerte herencia eurocéntrica implica un desequilibrio entre los ideales de aquellos que se benefician de ese modelo economicista, las empresas portuarias, y de aquellos que permanecen marginados en el proceso, las comunidades quilombolas de Santarém.

Palabras clave: desarrollo real; desarrollo económico; descolonialidad; el reconocimiento; proyectos portuarios.

\footnotetext{
${ }^{1}$ Universidade Federal de Goiás (UFG) e Universidade Alves Faria (UNIALFA), Goiânia, Goiás, Brasil.

${ }^{2}$ Universidade Federal de Goiás (UFG), Goiânia, Goiás, Brasil.
} 


\section{INTRODUÇÃO}

O artigo discute a ideia de desenvolvimento para além do viés econômico, tratando-o como instrumento para garantir a liberdade (SEN, 2009), em um viés decolonial. Busca-se diferenciar crescimento econômico de desenvolvimento (FURTADO, 1992), em uma concepção que pretende analisar outras perspectivas, como a social, a cultural e a ambiental.

O desenvolvimento é discutido, em um viés crítico, por meio do estudo da construção do terminal portuário da Empresa Brasileira de Portos de Santarém (EMBRAPS), e a relação de tal empreendimento com os saberes e necessidades locais. Para tanto, o texto adota, como método, o materialismo histórico, na perspectiva dialética de Enrique Dussel ${ }^{3}$ (2000), na perspectiva decolonial crítica de Aníbal Quijano (2005). As pesquisas bibliográfica, documental e jurisprudencial formaram a base metodológica, possibilitando a realização de uma análise crítica do projeto portuário da EMBRAPS em Santarém, no Pará, buscando, em especial, os olhares decoloniais de autores poucos lembrados, mesmo em discussões que tratam das problemáticas de seus países e de países vizinhos.

A decolonialidade parte de uma ruptura epistemológica, que apresenta as perspectivas dos conhecimentos até então subalternos em relação às construções eurocêntricas. Nesse sentido, conseguem englobar a realidade pós-colonial dos países latino-americanos, asiáticos, árabes e africanos, incluindo, também, as falas feministas, indígenas, negras, as de outras etnias e minorias. A ruptura com o pensamento colonial permite vislumbrar distintas e novas subjetividades que reconhecem e reagem às marcas coloniais, trazendo possibilidades de uma ecologia do ocidente e superação do modo de pensar dominante (QUIJANO, 2014).

Numa perspectiva colonial, o desenvolvimento se vê atrelado à ideia de progresso econômico e ao liberalismo, que acaba por marginalizar parte da sociedade que não se adéqua ou serve ao discurso dominante do modo de produção capitalista (VISVANATHAN, 2008 apud BALDI, 2014), invisibilizando os discursos contrários.

$\mathrm{Na}$ estrutura de poder que se instaura a partir do movimento colonial e que se reproduz na lógica globalizada, os países ditos subdesenvolvidos ou a parte "de baixo" do globo (imaginando mapa-múndi classicamente definido), ganham voz a partir de seus pesquisadores e de seus sujeitos, evidenciando a existência de outros modos de vida e de pensar o mundo- a partir do olhar decolonial (QUIJANO, 2005).

O principal argumento dessa nova perspectiva é a ressignificação de direitos historicamente negados, entendendo os lugares, seus sujeitos e relações a partir do principal ponto de vista para uma real compreensão (o daqueles que não só discutem, mas vivem a história). Em um desnovelo da globalização de seus conceitos (ESCOBAR, 2005), o desenvolvimento passa a ser repensado, ultrapassando a barreira economicista, para servir como um instrumento garantidor de liberdades dos cidadãos (SEN, 2009).

É nesse embate, sobre o que é desenvolvimento e sobre qual desenvolvimento está pautada a democracia brasileira, que se discute a instalação dos portos graneleiros de Santarém, no Estado

\footnotetext{
${ }^{3}$ Faz-se tal referência a fim de reconhecer as aproximações e pontos convergentes entre os pensamentos do alemão Kal Marx e do argentino Enrique Dussel, contudo, observando os contrapontos existentes. Enquanto Marx constrói sua argumentação considerando a existência de luta de classes, Dussel (2010) considera diferentes contextos e lugares de fala para perceber que o desenvolvimento histórico e político do mundo se segmenta em duas partes antagônicas: centro e periferia. Entendimento que se alinha com a ideia de colonialidade, instaurada com o descobrimento da América e perpetuada ao longo do tempo.
} 
do Pará. Em meio à judicialização dos conflitos, se discute qual desenvolvimento econômico decorrerá da construção do porto e de seus ganhos logísticos, bem como o desenvolvimento humano, social, cultural e ambiental, levando em conta os entraves pela preservação do meio ambiente e pelo reconhecimento dos sujeitos que integram aquele território.

Partindo dessa noção de decolonialidade, o artigo se abstém dos referenciais clássicos que integram a ideia de desenvolvimento, para adotar uma nova postura epistemológica a fim de refleti-lo. Nesse viés, busca compreender como os portos graneleiros estão sendo pensados e como se dá ou não a inclusão dos povos tradicionais nesse processo, bem como do interesse nacional em uma acepção mais ampla.

\section{DESENVOLVIMENTO E COLONIZAÇÃO: A IMPOSIÇÃO DO MODELO DE DESENVOLVIMENTO ECONÔMICO EUROPEU}

A colonialidade se funda na imposição de uma classificação racial e étnica, sendo o melhor instrumento de dominação capitalista, em especial para a consolidação da forma de pensar e organizar europeia ou "central" 4 sobre os novos territórios a serem "conquistados" (QUIJANO, 2014, p. 285-6).

A própria formulação e difusão do conhecimento, tido como clássico, em meados do século XVI e XVII, já demonstra a preocupação com os ideais eurocêntricos, se consolidando como forma de manter a hegemonia do modo de pensar europeu. Desde tal período, os conhecimentos, o pensamento e o modo de organizar daqueles que não ocupavam o "topo" das relações sociais não foram admitidas como válidos, portanto foram marginalizados ou mesmo extirpados (QUIJANO, 2005). A universalização de uma só ideia de desenvolvimento descartava o modo como as demais sociedades haviam se desenvolvido, afinal esses grupos eram "selvagens" e até desprovidos de humanidade.

É por isso que as feras são domadas e submetidas ao império do homem. Por esta razão, o homem manda na mulher, o adulto, na criança, o pai, no filho: isto quer dizer que os mais poderosos e os perfeitos dominam os mais fracos e os mais imperfeitos. Constata-se esta mesma situação entre os homens; pois há os que, por natureza, são senhores e outros que, por natureza, são servos. Os que ultrapassam os outros pela prudência e pela razão, mesmo que não os dominem pela força física, são, pela própria natureza, os senhores; por outro lado, os preguiçosos, os espíritos lentos, mesmo quando têm as forças físicas para realizar todas as tarefas necessárias, são, por natureza, servos. E é justo e útil que sejam servos, e vemos que isto é sancionado pela própria lei divina. Pois está escrito no livro dos provérbios: 'O tolo servirá o sábio'. Assim são as nações bárbaras e desumanas, estranhas à vida civil e aos costumes pacíficos. (SEPÚlVEDA, 1973).

Essa ideia de superioridade acabou por desconsiderar quaisquer outros modos de vida e de organização, tornando-se álibis inquestionáveis para a imposição do modo europeu. É nesse viés

\footnotetext{
${ }^{4}$ Enrique Dussel (2015) explica como a Europa se institui como centro do mundo a partir de 1492, com o "descobrimento" da América, colocando-se, por conseguinte, como centro da história mundial e parâmetro para as demais sociedades. Nesse sentido o termo "eurocentrismo" não se refere apenas à região europeia, mas a uma configuração global e hegemônica, que se forma a partir da Europa e da colonização. Falando de uma configuração de mundo moderna, ela se refere também aos Estados Unidos enquanto sociedade que assume posição central. Nesse entendimento, Quijano (2005) entende que, os demais espaços do globo que não têm status de centralidade ou topo restam à margem, como "periferia do mundo". Tal configuração se evidencia, por exemplo, nas discrepâncias entre Norte e Sul global.
} 
que a ideia de justiça cognitiva de Shiv Visvanathan revela, com bastante atualidade, a necessidade da reconstrução dos conhecimentos em sua própria validade cognitiva, sem tentar englobá-los na lógica já dominante. Nesse contexto, o autor assevera o paradoxo da modernidade, em que "uma sociedade que vê represas como templos da moderna Índia está agora de frente ao fato de que há mais refugiados dos projetos de desenvolvimento que de todas as guerras que foram travadas" (VISVANATHAN, 2008 apud BALDI, 2014, p. 16).

Avançando no tempo, o capitalismo segue na (re)elaboração das relações sociais, políticas e culturais de acordo com a máxima liberal e preponderante: a maximização do lucro. O lucro seria então o objetivo, alcançado pela lógica mercadológica, que possibilitaria um maior acúmulo de capital, com o consequente retorno desse capital no ciclo capitalista aumentando a produção, gerando empregos e mais crescimento econômico, levando ao verdadeiro desenvolvimento de determinada sociedade (SMITH, 1996).

Nessa visão, os países ainda não desenvolvidos deveriam passar por um processo de busca do desenvolvimento. Com esse intuito, alguns pensadores chegaram a estabelecer métodos para que um país se desenvolva, a exemplo de W.W. Rostow (1959) e as etapas do desenvolvimento, que previa a adoção de uma série de políticas econômicas de abertura.

Nos séculos que se seguem, o capitalismo se consolida e o liberalismo avança como ideologia dominante. Contudo o processo de globalização traz outra vertente ao liberalismo clássico (monoeconomismo): o liberalismo estrutural. Segundo essa corrente, a diferença entre os países de centro e de periferia deveriam ser observadas, pois restam claras as vantagens do primeiro sobre o segundo - o que o Argentino Raul Prebisch (2000) chamaria de "teoria da deterioração dos termos de troca".

Ao lado da crítica do teórico argentino, está o brasileiro Celso Furtado (1992) que revela uma assimetria entre o padrão de consumo dos países periféricos e dos ditos centrais, de modo que o primeiro tenta imitar o segundo e o seu processo tecnológico, contudo não leva em consideração que somente uma pequena parcela da população teria acesso aos melhores recursos. Para a correção desse problema, o autor sugere uma industrialização voltada para os anseios de toda a sociedade, em substituição às importações. Contudo essa não seria uma tarefa fácil pela pressão da parte mais abastada da sociedade.

Desse modo, é possível visualizar uma discussão do modelo liberal-capitalista imposto, ainda por quem defende a manutenção desse sistema ${ }^{5}$ e defende uma ascensão econômica dos países periféricos ou subdesenvolvidos, mas é necessário tecer uma crítica ainda mais consistente e fundamentada no próprio modo de construção do pensamento e da ideia de desenvolvimento.

As constituições dirigentes de Canotilho, as constituições sociais inspiradas na Constituição Mexicana de 1917 e na Constituição de Weimar, as constituições latino-americanas do último século, ou mesmo a Constituição Federal Brasileira de 1988, trazem em seus textos uma preocupação com o homem dotado de dignidade, a natureza, a cultura, a igualdade e a liberdade. Pontos que não podem ser invisibilizados ou postos de lado por motivos meramente econômicos. Desenvolver, sem levar em conta uma diversidade de fatores pode conduzir determinada sociedade a uma barbárie cultural, marginalizando quem não se adéqua às condições (im)postas, o que pôde ser acompanhado com o hodierno processo de globalização (ESCOBAR, 2005).

\footnotetext{
${ }^{5}$ O Banco Mundial (BM), por exemplo, traz, no sumário executivo de um diagnóstico sistemático do Brasil, uma série de apontamentos para que o país possa crescer, enfatizando, sobretudo, a necessidade de reduzir as desigualdades sociais e a degradação ambiental (BM, 2016).
} 
O desenvolvimento, ao longo da história, se confunde com o avanço do modo de pensar colonial, em que a economia é colocada sobre os demais aspectos da vida em sociedade. E é esse desenvolvimento, comumente confundido com o acúmulo de riquezas e transformado em fundamento do modo de produção capitalista, que passará a ser analisado nos tópicos a seguir. Afinal, o que é desenvolvimento?

\section{DECOLONIZANDO O CONCEITO DE DESENVOLVIMENTO}

Como uma verdade universal cristalizada, são definidos e estabelecidos espaços geopolíticos, assim ensinados e divulgados do início ao fim da formação escolar oficializada no Ocidente. Tratase de uma configuração que se vincula diretamente aos entendimentos e verdades que são reproduzidos mundialmente, presentes na cultura, no conhecimento e em todas as produções decorrentes destes. Logo, essa visão se reitera em todos os demais conceitos de uma sociedade, criando inúmeros campos epistêmicos e se reafirmando ciclicamente.

O mapa-múndi, usado de forma oficial, é um claro exemplo: uma representação geográfica, política, cultural, econômica e de poder que não condiz necessariamente com a realidade ${ }^{6}$. A conhecida dicotomia norte/sul ou desenvolvidos/subdesenvolvidos (ainda que haja países que geograficamente se localizem no sul global, mas que são sempre classificados como do norte por serem "mais desenvolvidos"), está permeada por uma noção específica de desenvolvimento. Essa noção traz o dito Norte como um modelo e alvo a ser perseguido pelos demais, integrantes do Sul.

É preciso então questionar como ou por que se forma esse conceito. Para tanto, as elaborações de Catherine Walsh (2005) jogam luz sobre o tema fazendo refletir que o próprio modo de pensar moderno traz uma marca geo-histórica, geopolítica, geocultural (e, por que não, geoeconômica?), que tem valor, cor e lugar determinados.

A construção e organização do sistema-mundo moderno é colonial (WALSH, 2005, p. $41)^{7}$. Nessa estrutura ou padrão de poder, que é mundial (QUIJANO, 2005, p. 117), a América surge como o primeiro espaço/tempo de um novo paradigma no mundo. As diferenças entre conquistados e conquistadores definiram as relações de dominação, ao mesmo tempo em que surge a relação de trabalho que gira em torno do mercado mundial. Assim, passam a se produzir identidades históricas vinculadas aos papéis que deveriam ser exercidos e aos locais determinados em que poderiam estar os sujeitos que exercem cada papel (QUIJANO, 2005, p. 118).

\footnotetext{
${ }^{6}$ Este mapa não retrata o mundo real, apesar de universalmente aceito (GALEANO, 1998). Nele, o norte ocupa 2/3 do planisfério enquanto o sul apenas 1/3. A América Latina é retratada como menor que a Europa ou que a soma de Estados Unidos e Canadá. Contudo, levando-se em conta as proporções reais, ela seria duas vezes maior que a Europa e bem maior os EUA e Canadá (GALEANO, 1998, p. 181). Portanto, trata-se de uma reafirmação de verdades universais e não uma representação geográfica.

${ }^{7}$ A autora traz como exemplo (em Interculturalidad, conocimentos y decolonialidad, p. 41) o pensamento filosófico de Immanuel Kant sobre o progresso nos âmbitos educacional, das artes e da ciência: apenas a raça branca europeia seria capaz de tal. Há uma hierarquização de cor de pele, no qual indígenas e negros ocupavam o patamar inferior. Ou seja, atribuiu-se à capacidade de produzir conhecimento lugar e cor. Esta questão influencia toda e qualquer produção (seja de conhecimento, econômica ou outra) entre norte/sul. Ora, se a verdade universal circulante a partir de Kant, seria que o que negros e indígenas produzem não representa qualquer progresso que a ciência considere, é hora de ponderarmos: de quais cores e povos se faz o sul do globo? E a América Latina? Logo, o conhecimento produzido aqui ou sua cultura, modo de desenvolvimento particular etc. não são igualmente válidos. Deve-se perseguir o modelo do primeiro mundo.
} 
Portanto, para todas as populações incorporadas ao sistema-mundo estabelecido pela Europa, houve um processo de (re)identificação histórica, em que essas sociedades receberam novas identidades geoculturais (QUIJANO, 2005) junto com uma dinâmica mundial de controle de mercados. Povos passam a se articular numa ordem global em torno da hegemonia ocidental e, nessa perspectiva, as relações são percebidas a partir da racionalidade e centralidade da Europa ocidental em detrimento da diversidade existente no mundo. Essa racionalidade traz em si um código de classificação para todas as coisas, em que a compreensão do mundo é feita por meio de dualidades: oriente e ocidente; mítico e científico; tradicional e moderno; irracional e racional; primitivo e civilizado, ou seja: "Europa e não-Europa" (QUIJANO, 2005, p. 121). No mesmo entendimento, acerca do desenvolvimento poderíamos pensar 'desenvolvido e subdesenvolvido' (ou não-desenvolvido).

Sendo assim, para elaborar uma reflexão que fuja a essa perspectiva colonial e desse padrão reiterado para pensar o desenvolvimento, recorre-se aqui a um pensamento diferente, em que o desenvolvimento não é um mero instrumento de classificação da população mundial em estratos socioeconômicos, mas sim um verdadeiro processo que favorece a expansão das liberdades humanas reais (SEN, 2009). Essa visão faz contraste com aquela que considera apenas o aumento dos números econômicos de um país, como aumento de renda e industrialização, para avaliar seu grau de desenvolvimento.

Conforme o pensamento de Amartya Sen (2009), a expansão das liberdades dos membros da sociedade é essencial para o desenvolvimento, já que elas influenciam diretamente nas disposições sociais, econômicas e nos direitos civis. Não se pode falar em desenvolvimento desconsiderando que deve haver na sociedade serviços de educação, saúde, bem como a participação de seus membros nas discussões e decisões públicas. A liberdade, vista como algo que o desenvolvimento promove, passa a ser o fim do desenvolvimento, que por sua vez adquire importância justamente por promover a liberdade-culminando no alargamento das liberdades substantivas (SEN, 2009, p. 17).

Nesse sentido, pressupõe-se necessária a remoção das "principais fontes de privação de liberdade: pobreza, tirania, carência de oportunidades econômicas e destituição social sistemática, negligência dos serviços públicos e intolerância ou interferência excessiva de Estados repressivos" (SEN, 2009, p. 18). O autor afirma que atualmente liberdades elementares são negadas a um grande número de pessoas e que a ausência destas pode estar relacionada diretamente com a pobreza econômica (que impede as pessoas de se alimentar, vestir e ter acesso a medicamentos, por exemplo).

A ideia de privação da liberdade substantiva se vincula ainda à falta de acesso aos serviços públicos, assistência social, assistência educacional e médica. Da violação da liberdade resulta também a negação de liberdades políticas e civis por regimes autoritários, com restrição das participações na vida social, política e econômica. Todos esses pontos são componentes construtivos do desenvolvimento real (e não apenas numérico) de uma sociedade. Contudo a visão tradicional (visão restritiva de desenvolvimento como crescimento industrial ou elevação do produto interno bruto apenas) não considera que a liberdade de participação política e a oportunidade de acesso aos serviços públicos atuem como indicadores de desenvolvimento.

Em uma nova concepção de liberdade segundo propõe a reflexão de Sen (2009), o desenvolvimento só poderia estar vinculado à possibilidade de suprimento de direitos fundamentais. Isso significa que desenvolvimento, de fato, quer dizer criação de possibilidades 
de geração de renda, bem como de sua distribuição e do acesso a direitos substanciais para a promoção eficaz do crescimento cultural, social, econômico, ambiental etc., em que a dignidade humana ocupe, de maneira lógica, o centro da vida em sociedade.

Para considerar a ótica supracitada, pensando o acesso dos indivíduos aos direitos essenciais como peça essencial para um desenvolvimento real e este como promotor das liberdades- e não com mero fim em si mesmo, é preciso retirar a fixação conceitual do termo desenvolvimento das convenções dualistas (desenvolvidos versus subdesenvolvidos). Não há uma fórmula mágica (industrialização, desmatamento, aumento de produção e subemprego) para se alcançar o desenvolvimento, até porque este deve ser pensado de uma forma complexa, não meramente econômica. Cada sociedade se estabelece e ocupa lugares específicos, que não podem e não devem ser invisibilizados pela ordem hegemônica. Não existe homogeneidade de recursos, história, culturas e sujeitos.

Nesse sentido, não há que se falar em sociedade que progrediu e sociedade que não progrediu, ao contrário, existem sociedades diferentes e com complexidades que variam de uma para outra. Da mesma forma, buscar o desenvolvimento não pode significar buscar o padrão europeu ou norte-americano, mas, antes de tudo, deve significar a busca por atendimento a um conjunto de liberdades substantivas que permitam a construção de uma sociedade plural e com menos desigualdade.

\subsection{Desenvolvimento social: o homem, o povo e seus direitos}

Se leituras decoloniais denunciam a parcialidade da produção de conhecimento e saberes, demonstrando a marginalização da produção daquilo que se convencionou chamar genericamente de "Terceiro Mundo", analisar a configuração do sistema mundial requer compreensão do modo como se reproduz a colonialidade ${ }^{8}$. Requer também perceber o surgimento dos processos decoloniais que reformulam as histórias locais das sociedades subalternizadas.

Falando em escala global, podem-se identificar os países ditos subdesenvolvidos como atores do espaço marginalizado. Se a lógica do discurso hegemônico de desenvolvimento for deixada de lado, surgem outros enunciados, o que revela a existência de um "locus enunciativo contra-hegemônico" em relação às verdades imputadas pela modernidade (NESKE, 2014). Tal sobreposição do colonizador sobre o colonizado se perpetuou na história pós-colonial, de modo que há uma inferiorização, não só dos sujeitos, como dos lugares - tidos como regiões incompetentes para alcançar o modelo estabelecido de desenvolvimento. Essas regiões serão rotuladas como subdesenvolvidas, atrasadas, e pobres devendo por isso servir àquelas que conseguem "sustentar" o mundo.

Entretanto, nessas localidades, existem interlocutores que, enunciando posições diversas à hegemônica, elaboraram uma construção positiva de si mesmos ressignificando direitos historicamente negados. Daí a importância de se notar os lugares, seus sujeitos e culturas, já que o desenraizamento (ou ausência de lugar) que decorre da globalização é um fator da condição moderna (ESCOBAR, 2005). De acordo com Escobar (2005), mesmo os pensadores da filosofia ocidental parecem ignorar a questão.

\footnotetext{
${ }^{8}$ Anibal Quijano (2005) diferencia o pensamento colonial, que se instala com o avanço europeu nos mares e os processos de "descobrimentos", e a sua perpetuação ou reprodução mesmo após o fim da colonização, que ele chama de colonialidade.
} 
A experiência com a localidade tem certa conexão com o cotidiano e traz consigo a noção de pertencimento, que inclui determinada dinâmica social, determinada cultura e economia, significativamente alterados nos processos de globalização (inéditos até o descobrimento das Américas). Partindo desse contexto, o lugar vai progressivamente sumindo no discurso da globalização, e esse esvanecer reflete na produção de conhecimento, na cultura e economia como um todo (ESCOBAR, 2005, p. 69).

Nos debates sobre desenvolvimento e ambiente, torna-se importante considerar novamente os lugares, a cultura, as racionalidades econômicas e ecológicas. Nessa percepção, a ecologia e o pós-desenvolvimento poderiam se propor a pensar ordens alternativas, incorporando práticas econômicas com base nas localidades. Apesar da interconectividade própria da modernidade, existem múltiplos vínculos entre lugar, poder e identidade (a criação de lugares acaba, por assim dizer, se aproximando também da "criação de gente" [ESCOBAR, 2005, p. 70]). Portanto, não há como falar em desenvolvimento social sem observar o locus do qual se fala e suas relações com os sujeitos que o ocupam bem como o grupo maior formado por estes sujeitos, o povo.

Tais relações (entre lugares e sujeitos) ganham destaque com as problematizações das atuais bases de produção no mundo, levantada pela preocupação ambiental (dentre outras). A partir daí, surgem proposições à elaboração de modelos de desenvolvimento que tenham o ser humano como fundamento ético e central do processo, a exemplo do chamado desenvolvimento sustentável. A ideia quer abarcar, além das questões ambientais, problemáticas sociais, culturais, políticas e territoriais. O homem é visto como o fim do desenvolvimento (COELHO; MELLO, 2011, p. 9) e, nesse sentido, deve-se reconhecer a sua dignidade, percebendo a ligação entre sustentabilidade, dignidade da pessoa humana e direitos fundamentais.

A noção de sustentabilidade vem com intenção de superar a ideia de economia com fim em si mesma, inserindo o reconhecimento da vida como fim e, assim, para ela existe o desenvolvimento. Nesse sentido, o bem-estar coletivo não se garante pela riqueza autônoma - crescimento econômico, mas pelo uso ou acesso que toda a coletividade tem e faz dela (GUIMARÃES, 1997, p. 16).

Subentende-se que a superação da crise do atual modelo de desenvolvimento requer uma percepção dos sujeitos de direito e dos componentes a eles relacionados (cultura, modos de vida e localidade) de forma que o fim desse desenvolvimento seja possibilitar a vida - com qualidade - desses sujeitos. Portanto deve-se reconfigurar a relação entre sociedade, indivíduos, poder político e economia, para superar invisibilidades e promover acesso a direitos fundamentais. Em tese, seria o espaço do Estado Democrático de Direito um ambiente propício para que se realizem essas mudanças, que não surgirão de forma espontânea, mas por meio das pressões sociais.

\section{QUE DESENVOLVIMENTO BUSCAMOS?}

A resposta à pergunta deste terceiro tópico não é algo consolidado, pois se entende o desenvolvimento, conforme exposto anteriormente, enquanto conceito em construção e dinâmico que se amolda a diferentes realidades sociais, econômicas e culturais. Contudo, a partir da análise de um caso concreto, ficam claras as dificuldades em estabelecer um conceito ou estratégias de desenvolvimento que reúnam diferentes perspectivas.

Dessa forma, a pretensão dos próximos parágrafos é refletir sobre o modelo de desenvolvimento adotado pelas instituições brasileiras e a sua (de)colonialidade, assim como 
confrontar a prática com a teoria abarcada pela Constituição brasileira de 1988, que, quando analisada, sistematicamente estabelece relevância a variados aspectos para além do econômico: tais como os sociais, os culturais e os ambientais.

\subsection{A construção do terminal portuário da EMBRAPS e a (des)construção de saberes locais}

A percepção da Amazônia como uma região marcada pela cultura indígena fez com que a escravidão, a cultura e saberes dos afrodescendentes fossem relegados, constituindo um vazio no inventário histórico da formação social paraense, fato que fica mais evidente na escassez de estudos sobre as comunidades negras, quilombolas, que se constituíram ao longo da história amazônica (FUNES, 1995).

O afrodescendente fez e faz parte do cotidiano amazônico, mesmo que invisibilizado pela sociedade e pela política de forma categórica e estratégica, desde a época da sua ocupação até os dias atuais.

A compreensão da importância da presença de africanos escravizados no Pará através das formas de sua inserção no século XVII coloca em pauta questões que não podem ter suas dimensões avaliadas apenas em função da expressividade numérica de escravos, cuja lógica de reprodução não se limita ao número de almas disponíveis nos plantéis. Antes se traduz na reiteração de relações de subordinação e poder que dão vida ao próprio sistema (SAMPAIO, 2011).

Através da interação desses sujeitos escravos e libertos, foi construída ${ }^{9}$, pelos laços de solidariedade, sua cultura, seu modo de viver e fazer diverso do modelo eurocêntrico, pautado em saberes próprios que os identificam e os diferenciam como desajustados sociais e rebeldes por seus senhores (REIS, 1940).

A identidade afro, no interior do Pará é uma construção histórica e social dinâmica, que entrelaça os processos de etnogênese, definidos por Bartolomé (2006), como a configuração de uma estrutura de diversidade humana em que grupos se separam tanto cultural quanto linguisticamente do grupo inicial a que pertencem, dando lugar a um novo tipo de coletividade social.

A esfera social proporciona a possibilidade de os sujeitos reconhecerem o outro na sua singularidade e originalidade, pelos laços de afetividade, respeito e solidariedade. Da perspectiva da teoria do reconhecimento (HONNETH, 2003), os atores da vida social não podem ser compreendidos separadamente do contexto moral ${ }^{10}$ e cultural em que estão inseridos.

A percepção do sujeito como diferente e desigual determina o início de um conflito, e uma luta por reconhecimento que busca mostrar, acima de tudo, que a centralidade da tensão está na análise do sujeito, da valoração normativa e do Estado que não perceberam, ou ignoraram, a condição do outro, ou ainda interpretaram de maneira equivocada suas intenções e seu contexto social e histórico próprios (RAVAGNANI, 2009, p. 48).

O espaço de luta a ser retratado no caso concreto da construção do porto graneleiro da EMBRAPS tem como sujeitos os quilombolas de Santarém, PA, cidade localizada à margem do Rio Tapajós, na região do Baixo Amazonas, no oeste do Estado do Pará, com aproximadamente

\footnotetext{
${ }^{9}$ A interação da qual se fala remete ao período da exploração do vale amazônico, das políticas pombalinas para incentivo da mão de obra escrava africana e aumento do tráfico negreiro dos séculos XVII a XIX.

${ }^{10}$ Esse contexto moral está subentendido nas práticas sociais e políticas de um povo, muito dificilmente expostos nos discursos explícitos.
} 
370 mil habitantes ${ }^{11}$. Está relativamente próxima à foz do rio Madeira, principal afluente do rio Amazonas, o que permite uma boa integração com outros estados amazônicos.

Até o ano de 2017, integravam o espaço social santareno 12 comunidades quilombolas, reconhecidas pela Federação das Organizações Quilombolas de Santarém (FOQS): Arapemã, Bom Jardim, Murumuru, Murumurutuba, Nova Vista do Ituqui, Patos do Ituqui, Pérola do Maicá, Saracura, São José do Ituqui, São Raimundo do Ituqui, Surubiú-Açú e Tiningú.

A possibilidade de os membros das comunidades quilombolas de Santarém referirem-se, positivamente, a si mesmo desse modo é o que se pode chamar de auto reconhecimento, pela sua capacidade de se considerar, na experiência do reconhecimento jurídico, como urna pessoa que partilha com todos os outros membros de sua coletividade as propriedades que os capacitam para a participação numa formação discursiva da vontade (HONNETH, 2003, p. 197).

Na Superintendência Regional do Instituto Nacional de Colonização e Reforma Agrária (Incra) no Oeste do Pará- SR30, 18 processos estão abertos relacionados à regularização de comunidades remanescentes de quilombos, dos quais, nove são do Município de Santarém; seis de Óbidos; três de Oriximiná ${ }^{12}$.

Em 2013, a EMBRAPS fez o pedido de licença ambiental junto à Secretaria de Meio Ambiente e Sustentabilidade do Estado do Pará (SEMAS-PA), para dar início ao projeto de construção do Terminal Portuário que movimentará granéis sólidos vegetais, previsto para ser instalado em área localizada na margem do Rio Amazonas, no bairro Área Verde, do Município de Santarém, PA. Uma região conhecida como "grande área do Maicá", zona de transição entre a área urbana, rural e de várzea.

Na proposta apresentada pelo Relatório de Impacto Ambiental do Porto EMBRAPS (FUNDAÇÃO DE AMPARO E DESENVOLVIMENTO DA PESQUISA [FADESP], 2013, p. 63), é defendida a existência das seguintes vantagens para o município de Santarém:

a) Potencialização de novos investimentos públicos e privados na região, fortalecendo a participação do município de Santarém na economia regional;

b) A abertura de novas oportunidades de trabalho durante as fases de implantação e operação do terminal portuário. Para esse cenário, preveem-se a geração de 700 empregos diretos, na fase de implantação, e mais 70 vagas no início de sua operação, além dos inúmeros postos de trabalhos indiretos, decorrente da necessidade de fornecimento de serviços de transporte, alimentação, saúde, segurança e lazer;

c) Potencialidade do crescimento econômico, com o aumento da geração de renda das populações locais, redução das desigualdades sociais e melhoria da qualidade de vida;

d) Promoção do desenvolvimento regional, através da geração de empregos, circulação de capitais, pagamento de impostos etc., potencializando o desenvolvimento do município de Santarém e do estado do Pará.

No entanto tal empreendimento impactará tanto direta quanto indiretamente nas relações sociais e ambientais das comunidades tradicionais quilombolas que habitam as margens do Lago do Maicá. Suas águas fornecem aos ribeirinhos o seu sustento, pois sobrevivem da intensa atividade da pesca artesanal e do turismo.

A situação portuária de Santarém, PA é conflituosa e marcada pelo desencontro das

\footnotetext{
${ }^{11}$ Dados do ano de 2016, extraídos do Instituto Brasileiro de Geografia e Estatística (IBGE).

${ }^{12}$ Atualizado em setembro de 2017.
} 
perspectivas na fronteira ${ }^{13}$ do agronegócio (MARTINS, 1997), que não observa limites de tradição popular histórica, do meio ambiente e do social, direcionando o olhar para a terra/água negócio, na condição de mercadoria, tomando para si a propriedade de dizer o que deve ou não ser feito a seu respeito.

Entre encontros e desencontros, em conflitos de fronteira, foi construído, em Santarém, PA, o Porto da Cargill, e há a perspectiva de construção do Porto da EMBRAPS, que têm como objeto o escoamento da produção de soja da região e do centro-oeste, impulsionando o mercado de grãos em detrimento do meio ambiente e do território de comunidades tradicionais.

Em 2000, o Ministério Público Federal propôs Ação Civil Pública n. 000016261.2000.4.01.3902, em trâmite na 1a Vara Federal de Santarém, PA, contra a Cargill e Secretaria de Estado de Meio Ambiente do Pará para que fossem paralisadas as obras do terminal da Cargill com a respectiva elaboração de estudo de impacto ambiental (EIA), e seu relatório (RIMA). No mesmo ano, houve concessão liminar da Justiça Federal cancelando as autorizações para o porto (PARÁ, 2000).

A Cargill recorreu da decisão liminar e obteve efeito suspensivo da medida, iniciando as obras apesar da pendência judicial. No ano de 2003, o terminal graneleiro começou a operar e permanece em operação até os dias atuais, apesar da Ação Civil ainda está em tramitação.

Em 2007, a pedido do MPF, o Instituto Brasileiro do Meio Ambiente e dos Recursos Naturais Renováveis (IBAMA) fechou o terminal graneleiro, porém, 20 dias depois, uma decisão do Tribunal Regional Federal da 1a Região ordenou a reabertura do Porto. Em 23 de abril do mesmo ano, aconteceu o julgamento do mérito do processo na segunda instância, mas a decisão só foi publicada quase seis meses depois, em 18 de outubro de 2007. O Tribunal Regional Federal da 1a região, em Brasília, rejeitou a apelação da empresa e manteve a sentença obrigando-a na elaboração do EIA/RIMA.

A decisão não deixou claro se o terminal devia ou não ser paralisado, a sentença foi alvo de recurso de ambas as partes envolvidas, e a questão foi levada ao Superior Tribunal de Justiça.

Em 2008, a Cargill recebeu da Secretaria de Estado e Meio Ambiente uma notificação que prorrogou novamente o prazo da licença de operação até abril 2009, com a possibilidade de prolongamento até julho do mesmo ano, desde que a Cargill adotasse medidas de controle ambiental que assegurem a preservação do meio ambiente, sob pena de suspensão/cassação da licença e interdição das atividades da empresa, reiterando a obrigação de apresentar, em caráter de urgência, o EIA RIMA.

Apesar das imposições citadas à Cargill, a decisão judicial acabou por favorecer a empresa, uma vez que a elaboração de Estudos de Impacto Ambiental e Relatório de Impacto ao Meio Ambiente, após mais de dez anos de funcionamento do porto, torna-se meramente formal e sem qualquer eficácia de proteção prática. Os impactos ambientais já ocorreram, tais como a aniquilação da praia da Vera Paz e de todo o ecossistema que compunha a região, sem que houvesse qualquer medida visando sua mitigação (COMISSÃO PASTORAL DA TERRA [CPT], 2010).

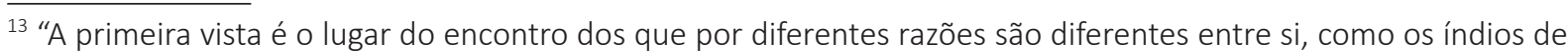
um lado e os civilizados de outro; como os grandes proprietários de terra, de um lado, e os camponeses pobres, de outro. Mas o conflito faz com que a fronteira seja essencialmente, a um só tempo, um lugar de descoberta do outro e de desencontro. Não só o desencontro e o conflito decorrentes das diferentes concepções de vida e visões de mundo de cada um desses grupos humanos. O desencontro na fronteira é o desencontro de temporalidades históricas, pois cada um desses grupos está situado diversamente no tempo da História" (MARTINS, 1997, p. 150-1).
} 
Graças à morosidade do judiciário brasileiro e à possibilidade de propor inúmeros recursos contra decisões judiciais, a Cargill ganha tempo e dinheiro, visto que o pórto segue em franca e legal operação.

Com o perigo iminente de que o porto graneleiro da EMBRAPS seja construído nos mesmos termos do porto Cargill, em fevereiro de 2016 o Ministério Público Federal e o Ministério Publico do Estado do Pará ingressaram na Justiça Federal pedindo a suspensão do licenciamento ambiental para a construção do porto da EMBRAPS, através da Ação Civil Pública n. 0377-75.2016.4.01.3902, em trâmite na 2a Vara Federal de Santarém, PA (PARÁ, 2016).

A Justiça Federal atendeu ao pedido liminar ordenando a paralisação do licenciamento do projeto. Desde então, a suspensão está em vigor até que os responsáveis pelo porto comprovem a realização da consulta prévia, livre e informada das comunidades quilombolas e povos tradicionais ${ }^{14}$ afetados pelo empreendimento.

A empresa EMBRAPS tentou retomar o projeto, em grau de recurso, mas o Tribunal Regional Federal da 1a Região (TRF1) manteve a decisão de primeira instância para suspender o empreendimento, até que os responsáveis pelo porto comprovem a realização da consulta, pois a instalação do terminal portuário terá reflexos diretos não só nos ecossistemas ali existentes, mas também em comunidades quilombolas e demais populares tradicionais ribeirinhas (PARÁ, 2017).

Para fundamentar a decisão, o TRF1 trouxe a liberdade como Direito Humano Fundamental através dos preceitos da Convenção Internacional 169, que estabelece as diretrizes para não discriminação dos povos indígenas e tribais e dos seus saberes.

A partir dessa decisão, a FOQS (s.d.) realizou, entre os meses de junho e agosto de 2016, com assessoria jurídica da Terra de Direitos ${ }^{15}$, oficinas preparatórias nas comunidades quilombolas para que definissem o modo como pretendem ser consultadas sobre projetos que representem riscos ao equilíbrio socioambiental dos territórios em que vivem e trabalham.

A judicialização dos conflitos agrários que permeiam as construções dos portos em Santarém, PA, não garante a resolução dos impactos aos territórios quilombolas e comunidades tradicionais, pois a decisão judicial que obriga a realização dos EIA/RIMA para a CARGILL não impediu seu funcionamento e instalação, enquanto que a decisão que suspendeu o licenciamento do porto EMBRAPS, até a realização da consulta prévia às comunidades que serão afetadas pelo projeto, não impede a especulação imobiliária no local para a expropriação silenciosa de comunitários que acabam vendendo suas terras por preço vil.

A invisibilização social e territorial dos sujeitos que são e serão afetados pelas "empreendedoras do agronegócio" desencadeia uma verdadeira luta para que as comunidades tradicionais locais sejam ouvidas. Revela-se uma memória que remete aos tempos da escravidão, dos quilombos e dos conflitos sociais que marcam as histórias dos afrodescendentes, cativos e libertos, que constituem as referências e o inventário necessários à compreensão da composição dessas comunidades e dos seus saberes.

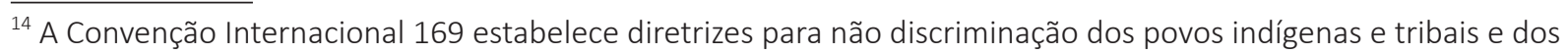
seus saberes, garantindo a consulta livre, prévia e informadas dos povos tradicionais que terão seu modo de viver e fazer impactados por grandes projetos do desenvolvimento.

${ }^{15}$ É uma organização de Direitos Humanos que atua na defesa, na promoção e na efetivação de direitos, especialmente os econômicos, sociais, culturais e ambientais (Dhesca). A organização surgiu em Curitiba, PR, em 2002, para atuar em situações de conflitos coletivos relacionados ao acesso à terra e aos Territórios rural e urbano. Atualmente, a Terra de Direitos incide nacional e internacionalmente nas Temáticas de direitos humanos e conta com escritórios em Santarém, PA, em Curitiba, PR, e em Brasília, DF.
} 


\section{CONCLUSÃO}

Ao longo de toda a história do Brasil, o escravizado teve e tem um papel de destaque muito maior do que se costuma admitir. O paradoxo é que, enquanto a vida de indivíduos traficados e escravizados era explorada, sendo fundamental para a economia europeia, o modo de vida próprio dessas pessoas era anulado. A desconsideração desses modos diversos de vida e a consideração pelo colonizador de só um modo válido de desenvolvimento e de saber - o europeu, são o centro do pensamento colonial em si. A exploração mercadológica da vida do outro em nenhum momento considera seus modos de vida, pelo contrário. Nesse sentido, a consolidação da economia e da política europeia se beneficiou dessa exploração, de modo que aquele considerado pelo pensamento colonial como um "ser atrasado", foi fundamental no processo de acumulação de capital de estabelecimento de uma centralidade no mundo.

O caso da construção dos portos em Santarém, PA é a representação de uma verdadeira luta dos sujeitos que querem dizer como querem ser ouvidos. Ao enfrentar uma experiência de desrespeito, esses sujeitos desencadeiam um processo de luta moral, social, política e legal, partindo de uma sequência de formas de reconhecimento recíproco entre os membros das comunidades quilombolas de Santarém.

A tentativa de invisibilização dos povos tradicionais, que vivem no local onde se pretende construir o empreendimento da EMBRAPS, reafirma uma lógica de poder colonial, tornando incontornável a observância do direito posto e o respeito ao direito fundamental de participação dessas coletividades culturalmente diferenciadas.

A tensão entre as práticas hegemônicas reiteradas e a existência persistente de modos de vida diversos se tornam evidentes, à medida que os indivíduos invisibilizados reclamam o seu papel de sujeito de direitos e resistem ao que tentam Ihes impor. Nesse exato momento, também emergem as ressignificações histórica e das relações entre povo e lugar ao longo dessa história. Ao mesmo tempo, essa emersão denuncia uma crise latente na noção de desenvolvimento que decorre do pensamento europeu e é levado a cabo mundo afora pelo "Norte" global.

Estabelece-se um impasse para o modelo de economia liberal em vigor: a superação da crise pressupõe a percepção dos novos sujeitos de direito, em luta. Por outro lado, esse reconhecimento pode refletir em alguma modificação, seja legislativa ou de configuração social e econômica que não convém aqueles que estiverem bem acomodados na estrutura já estabelecida. Significa que deverá haver alguma ponderação, e empreendimentos econômicos já não deveriam, em tese, fluir plenamente sem qualquer empecilho mesmo em face de lesões graves e reconhecidas a direitos de indivíduos direta ou indiretamente afetados. Por isso torna-se mais fácil invisibilizar do que dialogar, uma vez que, numa sociedade que se diz pautada pelo no Estado de Direito, chamar o outro à composição de conflitos e a qualquer diálogo importa antes em reconhecê-lo.

Repensar, ressignificar e rediscutir essas falas (im)postas como verdade são ações primordiais para o que o alcance de um desenvolvimento real, ou seja, aquele que é visto para além dos números divulgados pelos setores da economia, evidenciando uma composição complexa de fatores diversos que integram uma vida humana digna.

Se a história da América Latina está marcada pelo movimento colonial e seu modo de pensar, claramente a ideia de desenvolvimento que veio com esse pensamento se confunde com ele mesmo. Para refletir o tema numa perspectiva decolonial, é preciso então uma postura diversa: em que aspectos econômicos não figurem, em sobreposição, os demais aspectos da 
vida em sociedade. Trata-se de uma proposta audaciosa uma vez que sugere rever a primazia que o acúmulo de riquezas tem nas produções e reproduções do capitalismo, e que é o seu próprio fundamento.

Nesse sentido, o espírito de luta e resistência das comunidades remanescentes de quilombos em Santarém no Pará está vivo. Esses indivíduos, que agora se reconhecem como sujeitos de direitos, reivindicam seus direitos e o reconhecimento do outro (outro-sociedade, outro-Estado, outro-Capital e assim por diante). Não negam seu passado e buscam na sua ancestralidade a força para não aceitar a condição que Ihes é imposta. Negar o passado seria como buscar o mar onde tem rio e acreditar que o quilombo acabou em 1888, mas as vozes que o formam se fazem ouvir. Esse som revela tanto alguém, quem fala, quanto um lugar, de onde se fala.

\section{REFERÊNCIAS}

BALDI, C. A. Descolonizando o ensino de direitos humanos? Hendu-Revista LatinoAmericana de Direitos Humanos, Belém, PA, v. 5, n. 1, p. 8-18, 2014.

BARTOLOMÉ, M. A. As etnogêneses: velhos atores e novos papéis no cenário cultural e político. Mana, Rio de Janeiro, v. 12, n. 1, p. 39-68, abr. 2006.

BM. Retomando o caminho para a inclusão, crescimento e sustentabilidade. Relatório 101431-BR. Brasil: diagnóstico sistemático de país. Sumário Executivo. Maio 2016.

CARGILL NO MUNDO. Disponível em: http://www.cargill.com.br/pt/sobre-cargill-brasil/index.jsp. Acesso em: out. 2016.

COELHO, S. O.; MELLO, R. A. C. A sustentabilidade como um direito fundamental: a concretização da dignidade da pessoa humana e a necessidade de interdisciplinaridade do direito. Veredas do Direito, Belo Horizonte, v. 8, n. 15, p. 9-24, jan./jun. 2011.

CPT. CPT Santarém divulga Carta Aberta contra possibilidade de concessão de licença à Cargill no Pará. Santarém, 2010. Disponível em: https://www.cptnacional.org.br/publicacoes/noticias/cpt/293-cptsantarem-divulga-carta-aberta-contra-possibilidade-de-concessao-de-licenca-a-cargill-no-para. Acesso em: nov. 2017.

DUSSEL, E. Filosofia da libertação: crítica à ideologia da exclusão. 5. reimp. São Paulo: Paulus, 2015.

DUSSEL, E. Ética da libertação: na idade da globalização e da exclusão. Petrópolis, RJ: Vozes, 2000.

ESCOBAR, A. O lugar da natureza e a natureza do lugar: globalização ou pós-desenvolvimento? In: LANDER, E. (Org.). A colonialidade do saber: eurocentrismo e ciências sociais. Perspectivas latino-americanas. Buenos Aires: Consejo Latinoamericano de Ciencias Sociales (CLACSO), 2005. p. 69-86. Disponível em: https:// www.clacso.org.ar/libreria-latinoamericana/buscar_libro_detalle.php?id_libro=164. Acesso em: out. 2017.

FADESP. Relatório de Impacto Ambiental. Belém: Fundação de Amparo e Desenvolvimento da Pesquisa, 2013.

FOQS. Quilombolas de Santarém. [s.d.]. Disponível em: http://quilombolasdesantarem.blogspot.com. br/. Acesso em: out. 2017.

FUNES, E. Bom Jardim, Murumurutuba, Murumuru, Tiningu, Ituqui, Saracura,Arapemã. Terras de Afroamazonidas - "Nós já somos a reserva, somos os filhos deles". Arquivos UFOPA. 1995. Disponível em: 
http://www2.ufopa.edu.br/ufopa/arquivo/docdiv/2017/bom-jardim-murumurutuba-murumuru-tininguituqui-saracura-arapema.-terras-de-afro-amazonidas-201cnos-ja-somos-a-reserva-somos-os-filhosdeles201d/view. Acesso em: jan. 2017.

FURTADO, C. O subdesenvolvimento revisitado. Economia e Sociedade, Campinas, SP, v. 1, n. 1, p. 5-19, ago. 1992.

GALEANO, E. Patas arriba: la escuela del mundo al revés. 1998. Disponível em: http://resistir.info/livros/ galeano_patas_arriba.pdf. Acesso em: out. 2017.

GUIMARÃES, R. P. Desenvolvimento sustentável: da retórica à formulação de políticas públicas. In: BECKER, B. K.; MIRANDA, M. (Org.). A geografia política do desenvolvimento sustentável. Rio de Janeiro: UFRJ, 1997.

HONNETH, A. Luta por reconhecimento: a gramática moral dos conflitos sociais. Tradução Luiz Repa. São Paulo: Editora 34, 2003. 296p.

IBGE. Disponível em: http://www.cidades.ibge.gov.br. Acesso em: out. 2017.

MARTINS, J. S. M. Fronteira. A degradação do outro nos confins do humano. São Paulo: Hucitec, 1997.

NESKE, M. Z. Colonialidade e desenvolvimento: a ressignificação do lugar em "zonas marginalizadas" no sul do Rio Grande do Sul. 2014. Tese (Doutorado em Desenvolvimento Rural)- Universidade Federal do Rio Grande do Sul (UFRGS), Porto Alegre, 2014.

PARÁ. Tribunal Regional da 1ạ Região. Agravo de Instrumento n. 0027843-13.2016.4.01.0000. Empresa Brasileira de Portos de Santarém. Ministério Público do Estado do Pará. Relator: Desembargador Federal Souza Prudente. Brasília, DF, 31 de maio de 2016. Diário Oficial da União, Brasília, 24 maio 2017.

PARÁ (Estado). Ação civil pública 0377-75.2016.4.01.3902. Ministério Público Federal. Empresa Brasileira de Portos de Santarém, 15 de fevereiro 2016.

PARÁ (Estado). Ação civil pública 162-61.2000.4.01.3902. Ministério Público Federal. Cargill Agrícola AS. União Federal. Santarém, Estado do Pará, 17 de janeiro 2000.

PREBISCH, R. Problemas teóricos e práticos do crescimento econômico. In: BIELSHOWSKY, R. (Org.). Cinqüenta anos de pensamento da CEPAL. Rio de Janeiro: Record, 2000. p. 181-215.

QUIJANO, A. Colonialidad del podery classificación social. Buenos Aires: Consejo Latinoamericano de Ciencias Sociales (CLACSO), 2014. Disponível em: http://biblioteca.clacso.edu.ar/clacso/se/20140506032333/eje17.pdf. Acesso em: out. 2017.

QUIJANO, A. Colonialidade do poder, eurocentrismo e América Latina. In: LANDER, E. (Org.). A colonialidade do saber: eurocentrismo e ciências sociais. Perspectivas latino-americanas. Buenos Aires: Consejo Latinoamericano de Ciencias Sociales (CLACSO), 2005. p. 117-42. Disponível em: https://www.clacso.org. ar/libreria-latinoamericana/buscar_libro_detalle.php?id_libro=164. Acesso em: out. 2017.

RAVAGANI, H. B. Luta por reconhecimento: a filosofia social do jovem Hegel segundo Honneth. Kínesis, Marília, SP, v. I, n. 01, p. 39-57, 2009.

REIS, A. F. C. A política de Portugal no Vale Amazônico. Belém, PA: Revista Novidade, 1940.

ROSTOW, W.W. The stages of economic growth. The Economic History Review, London, Second Series, v. XII, n. 1, p. 1-16, 1959. 
SAMPAIO, P. M. Escravos e escravidão africana na Amazônia. In: SAMPAIO, P. M. (Org.). O fim do silêncio. Presença negra na Amazônia. Belém, PA: Açaí, 2011. p. 13-43.

SEN, A. Desenvolvimento com liberdade. São Paulo: Schwarcz, 2009.

SEPÚLVEDA, J. G. Tratado sobre las justas causas de la guerra contra los índios. In: ROMANO, R. Os mecanismos da conquista colonial: os conquistadores. São Paulo: Perspectiva, 1973. p. 84-5.

SMITH, A. A riqueza das nações. São Paulo: Nova cultural, 1996. (Col. Os economistas, v. 1).

WALSH, C. Interculturalidad, conocimientos y descolonialidad. Signo y Pensamiento, Bogotá, v. 24, n. 46, p. 39-50, jan./jun. 2005.

\section{Sobre os autores:}

Thiago Henrique Costa Silva: Doutorando do programa de pós-graduação em Agronegócio da Universidade Federal de Goiás. Mestre em Direito Agrário- UFG. Especialista em Direito Público pela Uni-Anhanguera-Goiás. Perito criminal da Superintendência de Polícia Técnico-Científica do Estado de Goiás. Professor I da UNIALFA-GO.E-mail: thiagocostasilva.jur@gmail.com

Renata Priscila Benevides de Sousa: Mestre do programa de pós-graduação em Direito Agrário da Universidade Federal de Goiás. Especialista em Direito Civil e Processo Civil pela PUC/GO. Advogada. Professora I da UNIALFA-GO. E-mail: renata-benevides@hotmail.com

Fabiana Ferreira Novaes: Mestre em Direito Agrário da Universidade Federal de Goiás. Especialista em Direito Ambiental pela Universidade Federal do Paraná. Mediadora e conciliadora pelo Tribunal de Justiça de Goiás. Advogada. E-mail: fabiananovaesjur@gmail.com

João da Cruz Gonçalves Neto: Doutor em Filosofia pela Pontifícia Universidade Católica do Rio Grande do Sul, mestre em Filosofia pela Universidade Federal de Goiás. Possui graduação em Filosofia pela Universidade Federal de Goiás (1989), graduado em Direito e em Filosofia pela Universidade Federal de Goiás. Pós-doutor em direito pela Universidade Federal de Santa Catarina. Atualmente é professor associado na Faculdade de Direito da Universidade Federal de Goiás e coordenador do Núcleo de Estudos e Pesquisas em Direitos Humanos da UFG. E-mail: dellacroce@dellacroce.pro.br 